\title{
Article \\ Effect of Sensory Deprivation of Nasal Respiratory on Behavior of C57BL/6J Mice
}

\author{
Yongji Zhu ${ }^{1,+}$, Yujing Ye ${ }^{1,+}$, Chenyang Zhou ${ }^{1,+}$, Siqi Sun ${ }^{1}$, Jingjing Zhang ${ }^{1}$, Zixuan Zhao ${ }^{1}$, Tingting Sun ${ }^{2}$, \\ Jing $\mathrm{Li}^{3}{ }^{3}$, Jing Yang ${ }^{1}$, Weiyun $\mathrm{Li}^{1, *}$ and Shanshan $\mathrm{Li}^{1, *}$ \\ 1 Department of Basic Medicine, School of Medicine, Zhejiang University City College, \\ Hangzhou 310015, China; zyj2901142505@163.com (Y.Z.); yyj000426@163.com (Y.Y.); \\ zhoucy9086@163.com (C.Z.); ssq44747@163.com (S.S.); hata6r@163.com (J.Z.); zzx001110@163.com (Z.Z.); \\ yangjing@zucc.edu.cn (J.Y.) \\ 2 College of Food Science and Pharmaceutical Engineering, Zaozhuang University, Zaozhuang 277160, China; \\ suntingting1218@126.com \\ 3 Institute of Neuroscience and Anatomy, School of Medicine, Zhejiang University, Hangzhou 310058, China; \\ lijing851@zju.edu.cn \\ * Correspondence: liweiyun@zucc.edu.cn (W.L.); liss0220@zucc.edu.cn (S.L.); Tel.: +86-571-8801-5208 (S.L.) \\ $\dagger$ These authors contributed equally to this work.
}

check for

updates

Citation: Zhu, Y.; Ye, Y.; Zhou, C.; Sun, S.; Zhang, J.; Zhao, Z.; Sun, T.; Li, J.; Yang, J.; Li, W.; et al. Effect of Sensory Deprivation of Nasal Respiratory on Behavior of C57BL/6J Mice. Brain Sci. 2021, 11, 1626. https://doi.org/10.3390/brainsci11121626

Academic Editors: Tifei Yuan,

Xiaochu Zhang, Di Zhao,

Dongsheng Zhou and Xinyou Lv

Received: 4 November 2021

Accepted: 6 December 2021

Published: 9 December 2021

Publisher's Note: MDPI stays neutral with regard to jurisdictional claims in published maps and institutional affiliations.

Copyright: (c) 2021 by the authors. Licensee MDPI, Basel, Switzerland. This article is an open access article distributed under the terms and conditions of the Creative Commons Attribution (CC BY) license (https:/ / creativecommons.org/licenses/by/ $4.0 /)$.

\begin{abstract}
Nasal breathing is a dynamic cortical organizer involved in various behaviors and states, such as locomotion, exploration, memory, emotion, introspection. However, the effect of sensory deprivation of nasal respiratory breath (NRD) on behavior remain poorly understood. Herein, general locomotor activity, emotion, learning and memory, social interaction, and mechanical pain were evaluated using a zinc sulfate nasal irrigation induced nasal respiratory sensory deprivation animal model $\left(\mathrm{ZnSO}_{4}-\right.$ induced mouse model). In the open field test, the elevated O-maze test, and forced swim test, NRD mice exhibited depressive and anxiety-like behaviors. In memory-associated tests, NRD mice showed cognitive impairments in the hippocampal-dependent memory ( $\mathrm{Y}$ maze, object recognition task, and contextual fear conditioning (CFC)) and amygdala-dependent memory (the tone-cued fear conditioning test (TFC)). Surprisingly, NRD mice did not display deficits in the acquisition of conditional fear in both CFC and TFC tests. Still, they showed significant memory retrieval impairment in TFC and enhanced memory retrieval in CFC. At the same time, in the social novelty test using a three-chamber setting, NRD mice showed impaired social and social novelty behavior. Lastly, in the von Frey filaments test, we found that the pain sensitivity of NRD mice was reduced. In conclusion, this NRD mouse model showed a variety of behavioral phenotypic changes, which could offer an important insight into the behavioral impacts of patients with anosmia or those with an impaired olfactory bulb (OB) (e.g., in COVID-19, Alzheimer's disease, Parkinson's disease, etc.).
\end{abstract}

Keywords: nasal breathing; sensory deprivation of nasal respiratory; behavioral test battery; C57BL/6J mice

\section{Introduction}

Respiration is an essential metabolic activity as it provides oxygen, which involves nasal breathing and mouth breathing. The respiratory drive is produced by conditional bursting pacemaker neurons in the brain stem [1]. However, scientists discovered that nasal breathing is not constant and can be altered by various emotions [2], cognitive states [3] and internal states [4]. Thus, respiration regulation is a complex process closely related to various behaviors and conditions.

Mammalian olfactory sensory neurons have dual functions as odor detectors and mechanical sensors for nasal breathing [5]. During nasal breathing, the airflow moves along the olfactory epithelium at the roof of the nasal cavity, triggering olfactory sensory neurons to respond to mechanical stimuli airflow via a cAMP cascade and to induce olfactory bulb (OB) neuronal oscillations, which lock to breathing cycles [5]. There is 
now substantial evidence in both rodents and humans that demonstrates a surprising cycle-by-cycle influence of nasal respiration on network activity throughout the olfactory system as well as much of the cerebral cortex, including primary olfactory (piriform) cortex [3], hippocampus [6], prefrontal cortex (PFC) [7,8] and somatosensory barrel cortex [9]. Respiration-entrained oscillations are a global brain rhythm and might aid long-range communication in the brain [10]. For example, during active behaviors, such as locomotion, sniffing, and exploration, PFC exhibits exclusive coupling between respiration and the $70-120-\mathrm{Hz}$ gamma sub-band; and the hippocampus exhibits coupling of the $40-90-\mathrm{Hz}$ and $110-160-\mathrm{Hz}$ gamma sub-bands to respiration [7]. With removal of olfactory bulb, naris occlusion, or destruction of nasal mucosa, the respiration-related oscillations in the $\mathrm{OB}$ are significantly weakened $[2,11]$. At the same time, the coherence and cross-correlation of $\mathrm{OB}$ with PFC activities [2], hippocampus activities [12], and barrel cortex activities [9] are also significant reduced. Although nasal breathing is closely related to the activity of multiple brain regions, studies on behavioral effects of nasal respiratory sensory deprivation (NRD) are scarce.

C57BL/6J wild-type mouse is an inbred mouse that is widely used as a background strain for mutant mice. In this experiment, it was used as the NRD model mouse, which were treated with zinc sulfate solution in the nasal cavity, leading to impair the perception of nasal breathing, such as breathing rate, inhalation time, and exhalation time [11,13]. Broad behavioral phenotyping was then performed within one week after zinc sulfate irrigation, with the use of open field [14] and elevated $\mathrm{O}$ maze [15] for locomotor activity and anxietybehavior assessment, forced swim for depression behavior [16], Y maze [17], novel object recognition [18] and contextual fear conditioning [19] for hippocampal-dependent memory, tone-cued fear conditioning for amygdala-dependent memory [20], social discrimination for social behavior [21], and von Frey filaments test for allodynia [22]. These behavioral tests were performed in a uniform manner following standardized protocols. Our results showed significant behavioral differences in almost all the tests, demonstrating the impacts of nasal breathing sensory deprivation on various behavior in C57BL/6J mice. The detailed characterization of behavioral changes related to nasal breathing sensory deprivation reinforces the importance of nasal breathing and provides a model reference for researchers in subsequent related studies.

\section{Materials and Methods}

\subsection{Animals}

A total of 104 wild-type C57BL/6J male mice aged 8-10 weeks were used. All the mice were group-housed under standard housing conditions with free access to food and water. All animal experiments complied with the ARRIVE guidelines and were conducted following the National Research Council's Guide for the Care and Use of Laboratory Animals and the guidelines for the Care and Use of Laboratory Animals of Zhejiang University City College.

\subsection{Nasal Irrigation of Zinc Sulfate}

To prevent zinc sulfate $\left(\mathrm{ZnSO}_{4}\right)$ from being inhaled into the lungs, the mice were held by the experimenter's hand without anesthesia, then $20 \mu \mathrm{L}$ of $0.17 \mathrm{M} \mathrm{ZnSO}_{4}$ or normal saline was slowly introduced into each naris of mice using a probe point (blunt) needle, 26 Gauge. Due to the regeneration of the olfactory epithelium, behavioral experiments were conducted within one week after zinc sulfate irrigation [13].

\subsection{Behavioral Test Battery}

Mice were handled for five days before testing. If the mice could crawl freely on the experimenter's hand and could be held in the experimenter's hand without fear, they would be divided into three groups randomly, by using the standard = RAND () function in Microsoft Excel. Different behavioral experiments were assigned to three groups and named the first group, the second group, and the third group. Then, the three animal groups 
were randomly assigned to different experiment groups. The first group underwent in the following order: open field, von Frey filaments test, and the contextual fear conditioning; the second group was used successively in the $Y$ maze, the novel object recognition test, and the cued fear conditioning test; and the third group was utilized in the social discrimination test, elevated O maze, and forced swim test (Figure 1). During the experiment, there were some precautions: (1) the interval between each behavioral experiment should be at least a day apart; (2) all behavioral tests were performed between 8:00 am and 8:00 pm; (3) one hour before testing, the mice were placed in the testing room for acclimatization to the room; (4) all behavior studies were conducted in different rooms with basically same environments; (5) after each experiment, the build-up of odor traces left by the previous mouse were removed with $75 \%$ ethanol to prevent interference with the next investigation; (6) all animals were euthanized with sodium pentobarbital approximately $24 \mathrm{~h}$ after the last behavioral assessment; and (7) if the data of individual mice was missing due to the dropout of equipment signal, these mice were excluded.

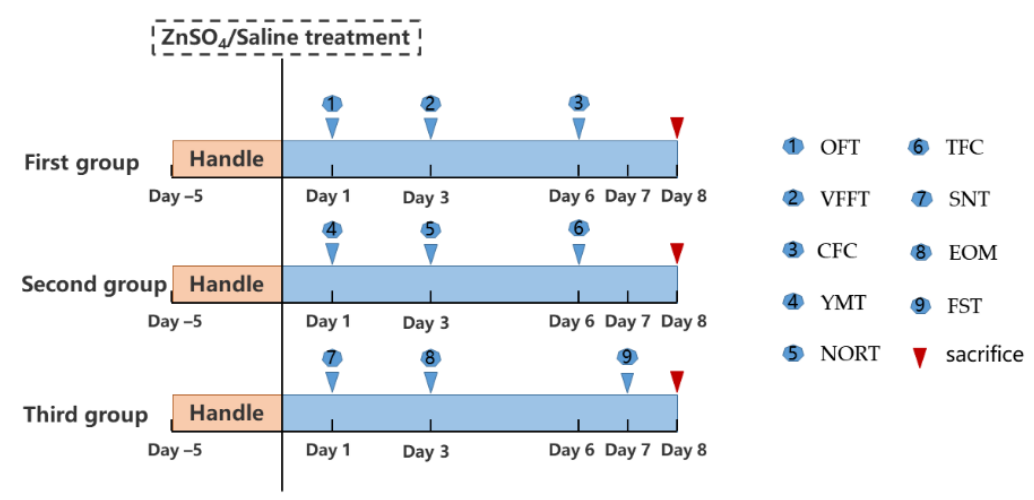

Figure 1. An illustration of the experimental timeline. Open field test, OFT; elevated O maze, EOM; forced swim test, FST; Y-maze test, YMT; novel object recognition test, NORT; contextual fear conditioning test, CFC; tone-cued fear conditioning test, TFC; social novelty test, SNT; von Frey filaments test, VFFT.

\subsubsection{Open Field Test (OFT)}

The OFT was performed to measure general locomotor activity and anxiety-behavior as previously described [14]. The custom-made open field apparatus consisted of a square arena ( $40 \mathrm{~cm} \times 40 \mathrm{~cm} \times 40 \mathrm{~cm}$, length $\times$ width $\times$ height) that was virtually divided into a center field (center, $20 \times 20 \mathrm{~cm}$ ) and a periphery field (Figure 2A). Each mouse was allowed to explore the test area for $10 \mathrm{~min}$. The test sessions were recorded by a video camera installed on the ceiling above the apparatus and analyzed using EthoVision tracking software (Noldus EthoVision XT10).

\subsubsection{Elevated O Maze (EOM)}

The EOM was conducted to assess anxiety-behavior according to previous report [15]. The custom-made $\mathrm{O}$ maze $(27 \mathrm{~cm} \times 6 \mathrm{~cm}$, inside diameter $\times$ width $)$ consisted of two equal open arms and two closed arms (surrounded by a 12-cm high black wall) elevated $75 \mathrm{~cm}$ from the ground (Figure 3A). The mouse was placed at the boundary between the open and closed arms, was allowed to explore for $10 \mathrm{~min}$, was tracked by a video camera installed on the ceiling above the $\mathrm{O}$ maze, and analyzed using EthoVision tracking software (Noldus EthoVision XT10). 
A

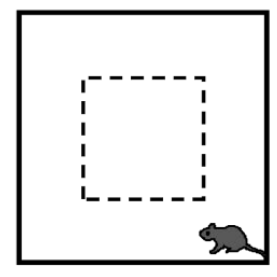

C

E
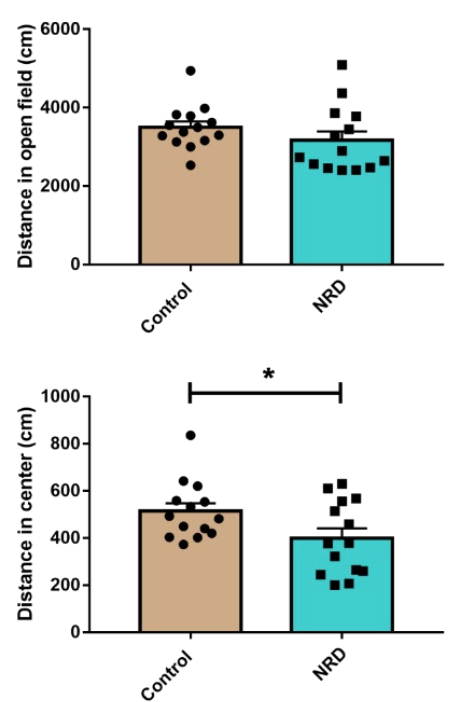

B

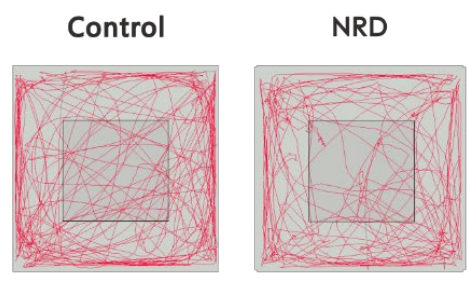

D

F
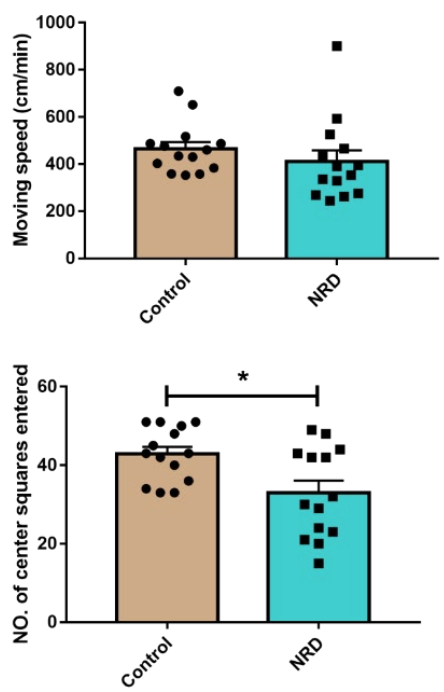

Figure 2. Normal locomotor activity and anxiety-like behavior in NRD mice. (A) Diagram of the open field apparatus (the peripheral (between solid and dotted lines) and central (inside the dotted line) regions). (B) Representation of the locomotion tracing for control and NRD mouse in the open field test. (C-F) Performances of the control and NRD mice in terms of distance in open field (C), moving speed in open field (D), in center zone (E), and number of center squares entered (F). ${ }^{*} p<0.05$ as determined by unpaired Student's $t$-test. Data are expressed as the means \pm SEMs. $n$ (control) $=14, n(\mathrm{NRD})=14$.

A

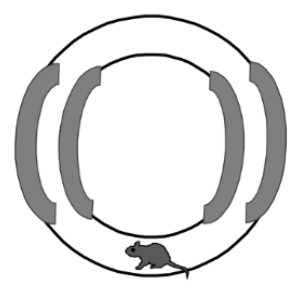

C

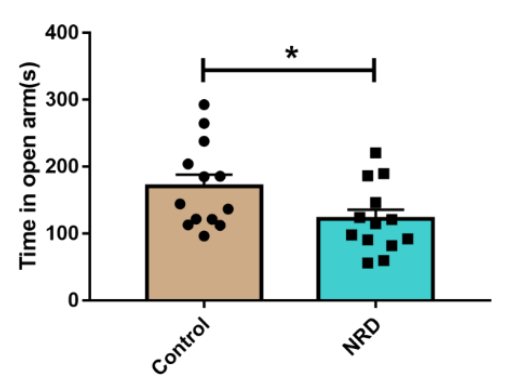

B

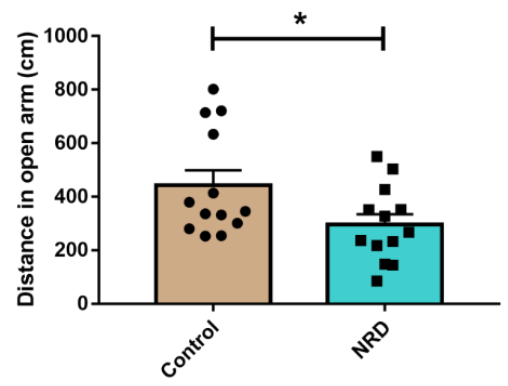

D

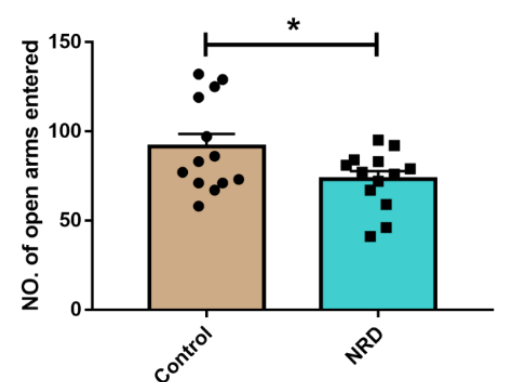

Figure 3. Anxiety-like behavior in NRD mice. (A) Diagram of the O-maze apparatus. (B-D) 
Performances of the control and NRD mice regarding the distance covered in open arms (B), time in open arms (C), and number of open arms entered (D). ${ }^{*} p<0.05$ as determined by unpaired Student's $t$-test. Data are expressed as the means \pm SEMs. $n$ (control) $=13, n(\mathrm{NRD})=13$.

\subsubsection{Forced Swim Test (FST)}

The FST was conducted to measure depression-behavior as previously described [16]. Each mouse was individually placed in an open cylindrical container $(14 \mathrm{~cm} \times 34 \mathrm{~cm}$, diameter $\times$ height) filled to a depth of $18 \mathrm{~cm}$ with $25 \pm 1{ }^{\circ} \mathrm{C}$ water and allowed to swim for 6 min (Figure 4A). Immobility was defined as no movement other than movement required to balance the body and keep the head above water. The behavior of the mice was video-recorded by a camera located in front of the container, and the struggle time of 2-6 min was analyzed three times by an experienced investigator who blinded to the experiment and the average value was taken.

A

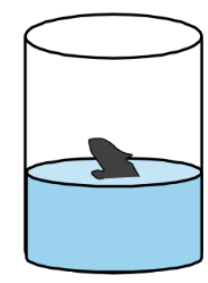

B

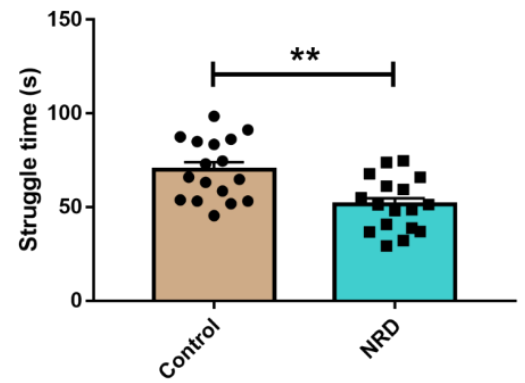

Figure 4. Decreased struggle time in NRD mice. (A) Diagram of the forced swim test. (B) Struggle times of the control and NRD mice in the forced swim test. ${ }^{* *} p<0.01$ as determined by unpaired Student's $t$-test. Data are expressed as the means \pm SEMs. $n$ (control) $=17, n(\mathrm{NRD})=17$.

\subsubsection{Y-Maze Test (YMT)}

The YMT was carried out to evaluate spatial working memory according to our previous report [23]. The custom-made Y-maze test was composed of three arms $(35 \mathrm{~cm}$ $\times 6 \mathrm{~cm} \times 15 \mathrm{~cm}$, length $\times$ width $\times$ height) labeled A, B, and C (Figure 5A). The mice were placed at the end of arm A, facing the maze's center, and were allowed to explore for $10 \mathrm{~min}$. The sequence of arm entries and the total number of entries were recorded by a video camera installed on the ceiling above the $Y$ maze for offline blind analysis. The three consecutive different choices of three arms were calculated as a correct alternation (i.e., ABC, BCA). The number of correct alternations was divided by the total number of triplets and multiplied by 100 to obtain Spontaneous Alternation (\%).

A

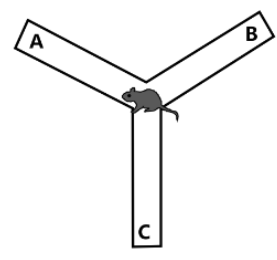

B

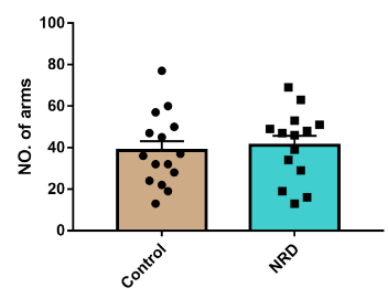

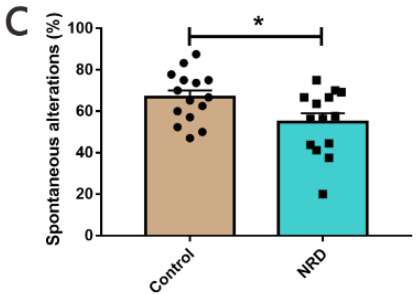

Figure 5. Impairment of Y-maze spontaneous alternation rate in NRD mice. (A) Diagram of the Y-maze working memory task. (B) The number of entries in all arm of the Y maze. (C) Spatial memory measured as alternation percentages in the $\mathrm{Y}$ maze. ${ }^{*} p<0.05$ as determined by unpaired Student's $t$-test. Data are expressed as the means \pm SEMs. $n$ (control) $=15, n(\mathrm{NRD})=14$. 


\subsubsection{Novel Object Recognition Test (NORT)}

The NORT was performed to assess declarative memory according to a previous report [24]. The apparatus for the NORT was an open square chamber $(40 \mathrm{~cm} \times 40 \mathrm{~cm} \times 40 \mathrm{~cm}$, length $\times$ width $\times$ height) (Figure $6 \mathrm{~A}$ ). After a 10-min habituation period in the chamber, the mouse was allowed to explore two identical objects A and B (approximately $6 \mathrm{~cm}$ from the walls) for $10 \mathrm{~min}$. After a retention period of $1 \mathrm{~h}$, familiar object $A$ was replaced with the novel object $C$, and the mouse was allowed to explore for $10 \mathrm{~min}$. Sniffing time was defined as the time when the subject's nose is within $2 \mathrm{~cm}$ of the object. The sniffing time spent on the new object and the old object was recorded in the last $10 \mathrm{~min}$ by EthoVision tracking software, and the NOR index was calculated as follows: (time to explore the novel object $C$ time to explore old object B)/(the total time to explore two objects).

A

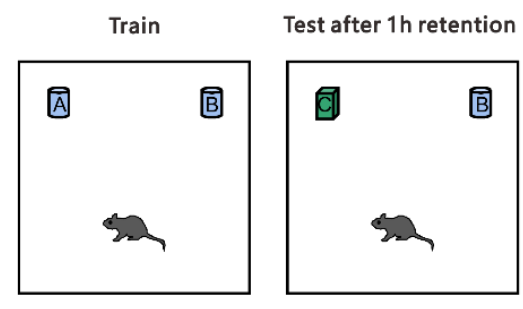

B

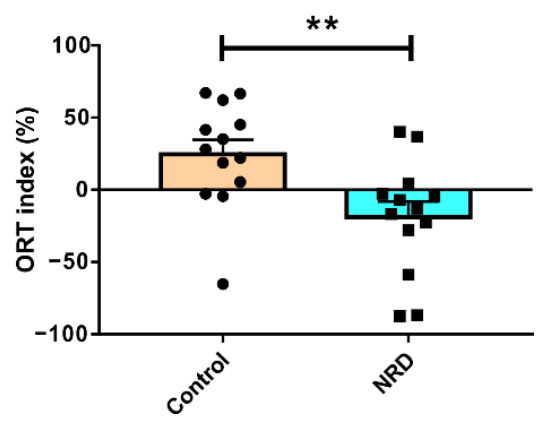

Figure 6. Defected cognition in object recognition memory in NRD mice. (A) Diagram of the novel object recognition test. (B) Performances of the control and NRD mice in the novel object recognition test. ${ }^{* *} p<0.01$ as determined by unpaired Student's $t$-test. Data are expressed as the means \pm SEMs. $n($ control $)=13, n(\mathrm{NRD})=13$.

\subsubsection{Contextual Fear Conditioning Test (CFC)}

The CFC test was performed to evaluate contextual fear conditional learning and memory as previously described [20]. During the training phase, the mice were first allowed to move freely for $2 \mathrm{~min}$ and were given a 2-s, $0.3 \mathrm{~mA}$ foot shock 3 times with an interval of $20 \mathrm{~s}$ in between (Figure 7A-train). Finally, the mice stayed in the chamber for another $2 \mathrm{~min}$ after the shock. One and $24 \mathrm{~h}$ after the training, the mice were placed on the platform again for $5 \mathrm{~min}$ (without foot shock) (Figure 7A-test), and their freezing behaviors were analyzed.

\subsubsection{Tone-Cued Fear Conditioning Test (TFC)}

The TFC was designed to assess tone-cued fear conditional learning and memory based on a previous report [20]. First, mice were trained within the same chamber with the contextual fear conditioning (Figure 8A-train). Training consisted of $2 \mathrm{~min}$ of free exploration, 3 tone-foot shock pairs ( $90 \mathrm{~s}$ apart, $30 \mathrm{~s}$ tone $(80 \mathrm{~dB}, 4 \mathrm{kHz})$ co-terminating with a 2-s, $0.5 \mathrm{~mA}$ foot shock) and another 2-min layover. After $1 \mathrm{~h}$ and $24 \mathrm{~h}$, to test the extent of fear, the trained mice were introduced in chamber 2 with a changed environment (shape, color, and floor), and the training process was repeated without giving foot shock (Figure 8A-test). The fear conditioning experiment was performed using the Fear Combined System (Panlab). The percentage of freezing time to tone alone was analyzed. 
A
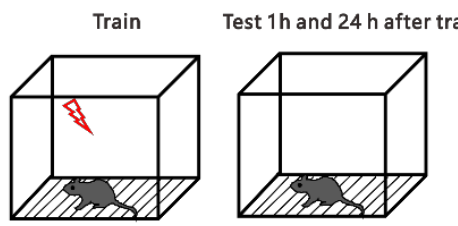

C

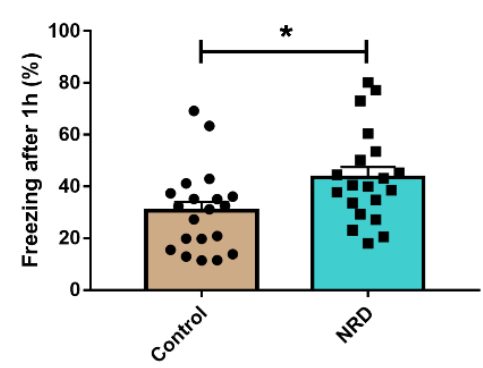

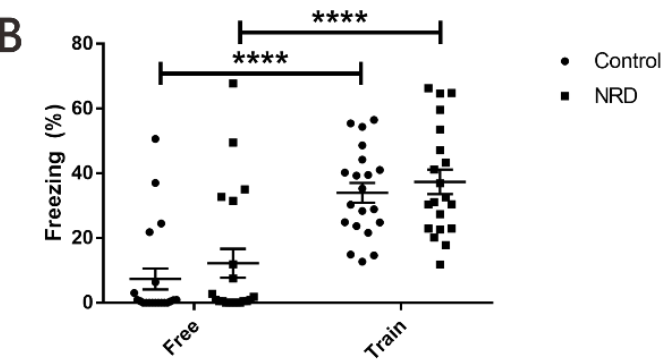

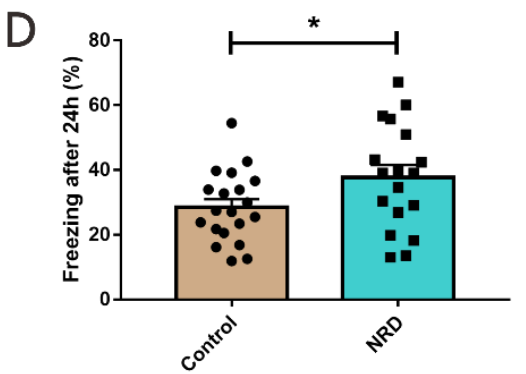

Figure 7. Enhanced contextual fear memory in NRD mice. (A) Diagram of the contextual fear conditioning test. (B) Performance of control mice and NRD mice before and during training. **** $p<0.0001$ as determined by the two-way ANOVA. $n$ (control) $=20, n$ (NRD) $=20$. (C) Freezing behavior tests after $1 \mathrm{~h}$ of training. $n$ (control) $=20, n(\mathrm{NRD})=20$. (D) Freezing behavior tests after $24 \mathrm{~h}$ of training. $n$ (control) $=20, n(\mathrm{NRD})=18{ }^{*} p<0.05$ as determined by the unpaired Student's $t$-test. Data are expressed as the means \pm SEMs.

A

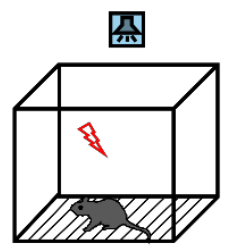

Train

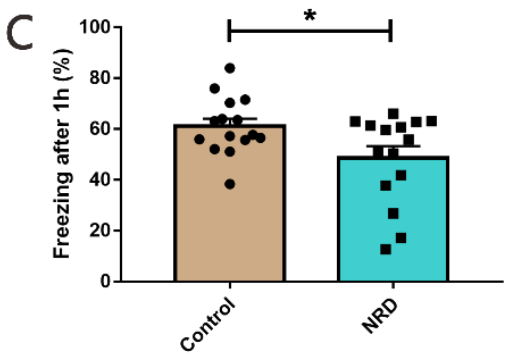

B
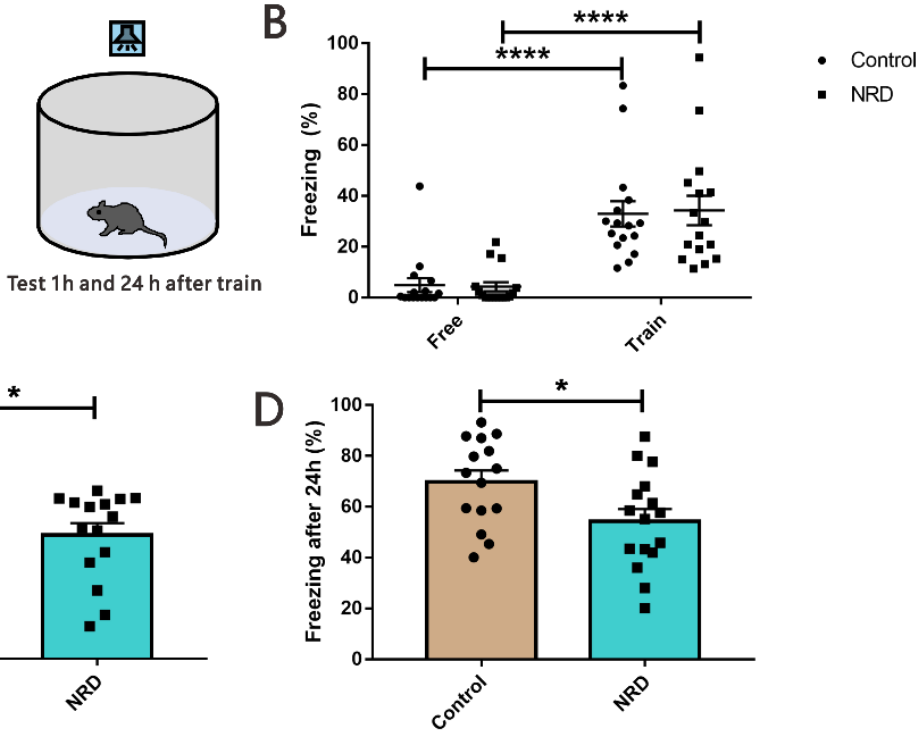

Figure 8. Reduced tone-cued fear memory in NRD mice. (A) Diagram of the cued fear conditioning test. (B) Performance of NRD mice and control mice before and during training. $n$ (control) $=16$, $n(\mathrm{NRD})=16$. (C) Freezing behavior tests after $1 \mathrm{~h}$ of training. $n$ (control) $=15, n(\mathrm{NRD})=15$. (D) Freezing behavior tests after $24 \mathrm{~h}$ of training. $n$ (control) $=15, n$ (NRD) $=16 .{ }^{*} p<0.05$, as determined by unpaired Student's $t$-test; ${ }^{* * * *} p<0.0001$ as determined by the two-way ANOVA. Data are expressed as the means \pm SEMs.

\subsubsection{Social Novelty Test (SNT)}

The SNT test was performed to evaluate social behavior as previously described [21]. The three-chamber test $(40 \mathrm{~cm} \times 40 \mathrm{~cm} \times 40 \mathrm{~cm}$, length $\times$ width $\times$ height $)$ consisted of a three-chamber apparatus including two mouse holders placed diagonally (Figure 9A). The trial comprised of three 10-min sessions without intertrial intervals (ITIs). In the 
first session (habituation), subject mice were allowed to acclimatize to the arena. In the second session (sociability), a never-before-met male mouse (stranger 1) was placed in one mouse holder while the other remained empty. In the third session (social novelty), the one stranger mouse remained unchanged, and another stranger mouse (stranger 2) was placed in the other mouse holder. The sniffing time was defined as the amount of time the subject mouse had its nose within $2 \mathrm{~cm}$ of a mouse holder. The test sessions were recorded by a video camera and analyzed using EthoVision tracking software (Noldus). A total of 52 C57BL/6J male strange mice (2-3 months of age) were used. Each mouse was used only once for each experiment.

A

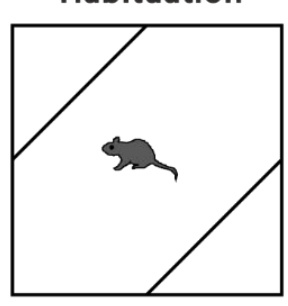

B

Sociability

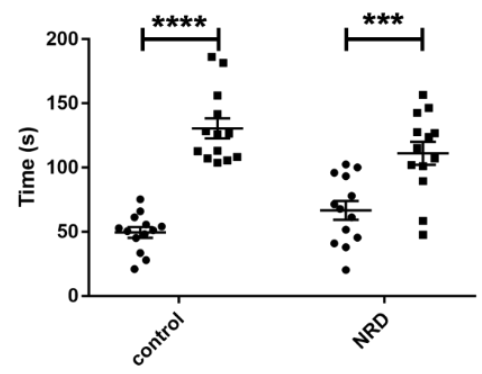

D

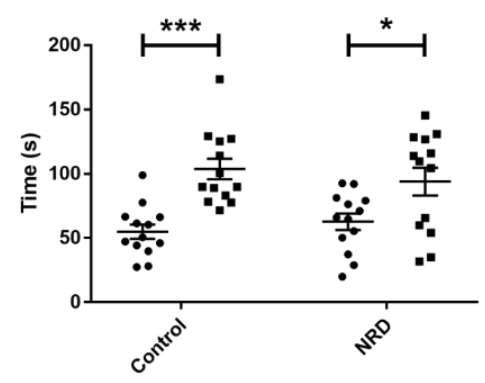

Social Novelty
Sociability

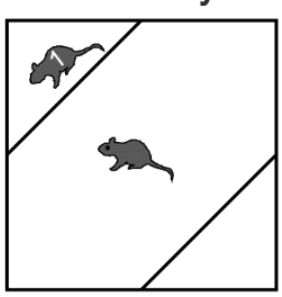

C

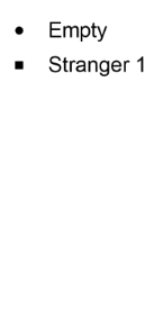

- Stranger1

- Stranger 2

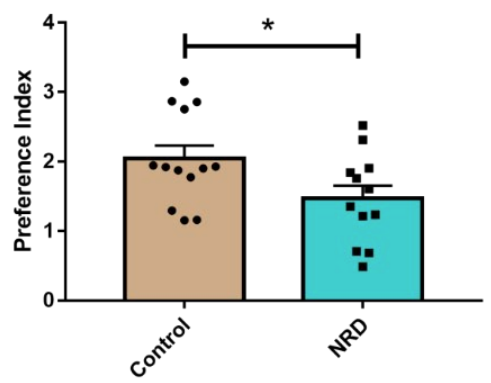

Figure 9. Both social behavior and social novelty behavior were impaired in NRD mice. (A) Diagram of the social novelty test. (B) Sniffing time of empty and stranger 1in the control and NRD mice during sociability session. ${ }^{*} p<0.05,{ }^{* * *} p<0.001$, as determined by the two-way ANOVA. (C) Quantitative sociability assessment. ${ }^{* *} p<0.01$ as determined by unpaired Student's $t$-test. (D) Sniffing time of stranger 1 and stranger 2 in the control and NRD mice during social novelty session. ${ }^{* * *} p<0.001,{ }^{* * * *} p<0.0001$, as determined by the two-way ANOVA. (E) Quantitative social novelty assessment. ${ }^{*} p<0.05$ as determined by unpaired Student's $t$-test. Data are expressed as the means \pm SEMs. $n$ (control) $=13, n(\mathrm{NRD})=13$.

\subsubsection{Von Frey Filaments Test (VFFT)}

The protocol for VFFT was referred to Chaplan SR, et al. to assess allodynia [22]. Mice were allowed to acclimate to plexiglass enclosures on top of a wire testing rack for $30 \mathrm{~min}$ before each test session (Figure 10A). After habituation, responses (withdrawal, shaking, or licking the paw) to mechanical stimulation in the middle area of the left hind paw were 
determined by applying the von Frey filaments using an up-down technique. The 50\% threshold is calculated based on previous research [22].

A

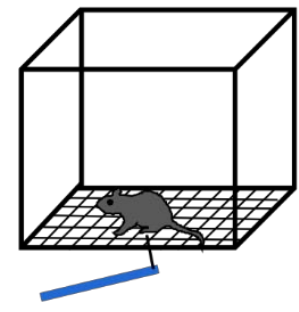

B

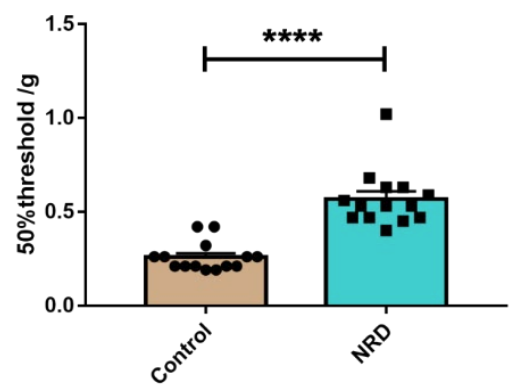

Figure 10. Declined pain sensitivity in NRD mice. (A) Schematic of von Frey filaments test. (B) Quantitative allodynia assessment by fifty percent paw withdrawal threshold testing. ${ }^{* * * *} p<0.0001$ as determined by unpaired Student's $t$-test. Data are expressed as the means \pm SEMs. $n$ (control) $=$ $14, n(\mathrm{NRD})=14$.

\subsubsection{Food-Seeking Test}

To evaluate the effect of zinc sulfate irrigation on the olfaction of mice, the food-seeking test at 1 and 7 days after nasal irrigation was performed as our previous described [17]. Briefly, $1 \times 1-\mathrm{cm}$ food particle was buried $3 \mathrm{~cm}$ underneath the bedding in the middle of the cage. After fasting for $24 \mathrm{~h}$, subjects went into the cage to search for hidden food for $300 \mathrm{~s}$. The latency to find the food and begin to eat was recorded. If the subject did not find the buried food within $300 \mathrm{~s}$, the test was stopped and recorded for $300 \mathrm{~s}$.

\subsubsection{Statistical Analysis}

The data were analyzed using GraphPad Prism version 7.0. The values are presented as the mean \pm SEM. A $p$-value $<0.05$ was considered statistically significant. The statistical significance of the differences in the conditional fear test and social novelty test was assessed by two-way ANOVA followed by Bonferroni posttests. For the rest of the data, comparisons of the means between two groups were performed using the unpaired Student's $t$-test. The data for each test are summarized in Table 1.

Table 1. Summary of data from the behavioral experiments.

\begin{tabular}{|c|c|c|c|c|c|c|c|}
\hline & & \multicolumn{2}{|c|}{ Control } & \multicolumn{2}{|l|}{ NRD } & \multirow{2}{*}{$p$-Value } & \multirow{2}{*}{ df } \\
\hline & & Mean \pm SEM & $n$ & Mean \pm SEM & $n$ & & \\
\hline \multirow{4}{*}{ OFT } & Distance in open field & $3499 \pm 149.5$ & 14 & $3171 \pm 224$ & 14 & 0.2336 & 26 \\
\hline & $\begin{array}{l}\text { Moving speed in open } \\
\text { field }\end{array}$ & $465 \pm 28.35$ & 14 & $412.5 \pm 46.51$ & 14 & 0.3437 & 26 \\
\hline & Distance in center & $514.9 \pm 33.11$ & 14 & $399.6 \pm 41.42$ & 14 & 0.0390 & 26 \\
\hline & $\begin{array}{l}\text { Number of center } \\
\text { squares entered }\end{array}$ & $42.86 \pm 1.83$ & 14 & $33 \pm 3.063$ & 14 & 0.0104 & 26 \\
\hline \multirow{3}{*}{$\mathrm{EOM}$} & Distance in open arms & $443.6 \pm 55.05$ & 13 & $295.7 \pm 38.91$ & 13 & 0.0381 & 24 \\
\hline & Time in open arms & $170.6 \pm 17.67$ & 13 & $121.8 \pm 14.18$ & 13 & 0.0414 & 24 \\
\hline & $\begin{array}{l}\text { Number of open arms } \\
\text { entered }\end{array}$ & $91.38 \pm 7.238$ & 13 & $73.23 \pm 4.512$ & 13 & 0.0438 & 24 \\
\hline FST & Struggle times & $69.96 \pm 3.945$ & 17 & $51.28 \pm 3.468$ & 17 & 0.0012 & 32 \\
\hline \multirow{2}{*}{ YMT } & Number of arms & $38.6 \pm 4.498$ & 15 & $41.14 \pm 4.555$ & 14 & 0.6946 & 27 \\
\hline & Spontaneous alternation & $66.88 \pm 3.128$ & 15 & $54.88 \pm 4.157$ & 14 & 0.0276 & 27 \\
\hline NORT & ORT index (\%) & $24.56 \pm 10.08$ & 13 & $-18.98 \pm 10.95$ & 13 & 0.0074 & 24 \\
\hline
\end{tabular}


Table 1. Cont.

\begin{tabular}{|c|c|c|c|c|c|c|c|}
\hline & & \multicolumn{2}{|c|}{ Control } & \multicolumn{2}{|l|}{ NRD } & \multirow{2}{*}{$p$-Value } & \multirow{2}{*}{ df } \\
\hline & & Mean \pm SEM & $n$ & Mean \pm SEM & $n$ & & \\
\hline \multirow{4}{*}{$\begin{array}{c}\text { FCT } \\
\text { (freezing } \\
\% \text { ) }\end{array}$} & Free & $7.347 \pm 3.237$ & 20 & $12.22 \pm 4.46$ & 20 & 0.3826 & 38 \\
\hline & Train & $33.96 \pm 3.05$ & 20 & $37.38 \pm 3.791$ & 20 & 0.4864 & 38 \\
\hline & After $1 \mathrm{~h}$ & $30.5 \pm 3.567$ & 20 & $43.55 \pm 4.01$ & 20 & 0.0199 & 38 \\
\hline & After $24 \mathrm{~h}$ & $28.52 \pm 2.431$ & 20 & $37.78 \pm 3.809$ & 18 & 0.0436 & 36 \\
\hline \multirow{4}{*}{$\begin{array}{c}\text { TCF } \\
\text { (freezing } \\
\% \text { ) }\end{array}$} & Free & $4.883 \pm 2.757$ & 16 & $4.258 \pm 1.788$ & 16 & 0.8504 & 30 \\
\hline & Train & $32.93 \pm 4.959$ & 16 & $34.26 \pm 5.783$ & 16 & 0.8619 & 30 \\
\hline & After $1 \mathrm{~h}$ & $61.14 \pm 2.89$ & 15 & $48.71 \pm 4.538$ & 15 & 0.0285 & 28 \\
\hline & After $24 \mathrm{~h}$ & $69.89 \pm 4.398$ & 15 & $54.38 \pm 4.723$ & 16 & 0.0233 & 29 \\
\hline \multirow{6}{*}{ SNT } & Sociability; empty & $49.52 \pm 4.164$ & 13 & $66.78 \pm 7.364$ & 13 & 0.0525 & 24 \\
\hline & Sociability; stanger1 & $130.6 \pm 7.801$ & 13 & $111.3 \pm 8.946$ & 13 & 0.1157 & 24 \\
\hline & Sociability; assessment & $2.64 \pm 0.2201$ & 13 & $1.762 \pm 0.1841$ & 13 & 0.0054 & 24 \\
\hline & Social novelty; stranger1 & $71.12 \pm 10.32$ & 13 & $62.69 \pm 6.437$ & 13 & 0.4951 & 24 \\
\hline & Social novelty; stranger2 & $103.7 \pm 8.037$ & 13 & $93.97 \pm 10.85$ & 13 & 0.4763 & 24 \\
\hline & $\begin{array}{l}\text { Social novelty; } \\
\text { assessment }\end{array}$ & $2.046 \pm 0.1855$ & 13 & $1.469 \pm 0.1854$ & 12 & 0.0386 & 23 \\
\hline VFFT & $\begin{array}{l}50 \% \text { mechanical } \\
\text { threshold }\end{array}$ & $0.2593 \pm 0.02058$ & 14 & $0.5686 \pm 0.04063$ & 14 & $<0.0001$ & 26 \\
\hline
\end{tabular}

\section{Results}

\subsection{Open Field Test}

Exploratory behavior in a novel environment and general locomotor activity were assessed in an open field for $10 \mathrm{~min}$ (Figure 2A,B). The total distance covered within $10 \mathrm{~min}$ was $(3171 \pm 224) \mathrm{cm}$ in the NRD group and $(3499 \pm 149.5) \mathrm{cm}$ in the control group (Figure 2C). The average speed of the NRD group was $(412.5 \pm 46.51) \mathrm{cm} / \mathrm{min}$, and that of the control group was $(465 \pm 28.35) \mathrm{cm} / \mathrm{min}$ (Figure 2D). The NRD mice did not achieve statistical significance for either distance traveled or moving speed in the open field ( $p=0.2336, p=0.3437$, respectively; Figure 2C,D). The data pertaining to the distance traveled in the center zone or the number of entries can be used to analyze the anxiety behavior of mice. The total distance of activity within $10 \mathrm{~min}$ in the central zone in the NRD group was $(399.6 \pm 41.42) \mathrm{cm}$, and that of the control group was $(514.9 \pm 33.11) \mathrm{cm}$ $(p=0.039$, Figure 3E). The number of the NRD group central zone entries was $(33 \pm 3.063)$ times compared to $(42.86 \pm 1.83)$ times for the control group $(p=0.0104$, Figure $2 \mathrm{~F})$.

\subsection{Elevated O Maze}

Next, the elevated O-maze test was performed to evaluate anxiety in mouse models (Figure 3A). Compared to the control mice, the NRD mice traveled a shorter distance $(p=0.0381$, Figure 3B), spent less time $(p=0.0414$, Figure 3C), and had fewer number of entries $(p=0.0438$, Figure 3D) in the open arms.

\subsection{Forced Swim Test}

To further assess the depressive state of our mouse model, we utilized a forced swim test (Figure 4A). Interestingly, we found that the NRD mice spent less time struggling than the control mice $(p=0.0012$, Figure 4B). 


\subsection{Y-Maze Test}

To evaluate whether the sensory deprivation of nasal breathing might affect spatial working memory, we used the Y-maze spontaneous alternation test for further behavioral assessment (Figure 5A). No difference between NRD mice and control mice was detected for the total number of arm entries, indicating that the exploratory disposition of NRD mice was not altered compared to control mice ( $p=0.6946$, Figure 5B). However, the NRD mice showed a deficit in spontaneous alternation $(p=0.0276$, Figure $5 C)$.

\subsection{Novel Object Recognition Test}

We then assessed the declarative memory of mouse models using the object recognition test, which measures an animal's ability to distinguish between novel and familiar objects (Figure 6A). After a retention phase of $1 \mathrm{~h}$, the testing phase revealed that the NRD mice displayed a significantly lower discrimination ORT index than control animals $(p=0.0074$, Figure 6B).

\subsection{Fear Conditioning Test}

The contextual and the tone-cued fear conditioning tests were used to evaluate conditional learning and memory. In the contextual conditioning test, compared with the state before and during training, the performance of NRD mice and control mice was similar, the freezing time was significantly increased $(p<0.0001, p<0.0001$, respectively; Figure 7B), but there was no significant difference $(p>0.9999, p>0.9999$, respectively; Figure 7B) between the NRD and control mice. Interestingly, in the memory retrieval phase, the NRD mice had a longer freezing time in contrast to the control mice $(p=0.0199$, Figure 7C; $p=0.0436$, Figure 7D). In the tone-cued fear conditioning test, NRD mice did not display deficits in freezing acquisition ( $p>0.9999$, Figure 8B), but they showed significant memory retrieval impairment following $1 \mathrm{~h}$ and $24 \mathrm{~h}$ after training $(p=0.0285$, Figure $8 \mathrm{C} ; p=0.0233$, Figure 8D).

\subsection{Social Novelty Test}

The social behavior was assessed using the three-chamber paradigm test (Figure 9A). The experiment consisted of three parts: training phase, social phase, and social novelty phase. During the social phase, both NRD and control mice showed similar performances, preferring to sniff stranger 1 versus sniffing the empty cage $(p<0.0001, p=0.0008$, respectively; Figure 9B), but NRD mice spent significantly less time in the interaction zone $(p=0.0054$, Figure 9C). Consistently, during the subsequent social novelty test, both mice spent more time sniffing stranger 2 than stranger 1 ( $p=0.0004, p=0.0381$, respectively; Figure 8D). However, the preference index (ratio of time sniffing stranger 2 vs. stranger 1) revealed that the NRD mice had a significantly decreased preference for stranger 2 $(p=0.0386$, Figure 9E).

\subsection{Von Frey Filaments Test}

The von Frey filaments test was used to assess allodynia (Figure 10A). The $50 \%$ mechanical thresholds of the NRD group and the control group were $0.5686 \pm 0.04063 \mathrm{~g}$ and $0.2593 \pm$ $0.02058 \mathrm{~g}$, respectively $(p<0.0001$, Figure 10B). The data showed that the $50 \%$ mechanical threshold of the NRD group was significantly higher than that of the control group.

\section{Discussion}

Nasal breathing is a ubiquitous organizer of dynamics across multiple brain areas and is simultaneously involved in various behaviors and states $[10,25]$. In this present study, general locomotor activity, emotion, learning and memory, social interaction, and mechanical pain were evaluated in a $\mathrm{ZnSO}_{4}$-induced mouse model to explore the behavioral effects of NRD.

Breathing is affected by emotions, such as sadness, happiness, or anxiety [26]; in turn, breathing control can also improve emotions [27]. But whether the sensory deprivation of 
nasal breathing can impact emotion is not known. To that end, we assessed the depression and anxiety state of mouse models using the open field, elevated $\mathrm{O}$ maze, and forced swim tests [14-16].

In the open field test, we found that the distance and shuttle times of the NRD mice in the central area were reduced, but the total distance and average speed in the open field had no significant difference. Meanwhile, the cumulative time, distance, and number of shuttles of NRD mice in the elevated O-maze open arms decreased, indicating that NRD may cause anxiety-like behaviors rather than reduced motor activity. Similarly, the struggle time of forced swim was also reduced, indicating that NRD can also induce depressionlike behavior. There are numerous lines of evidence demonstrating that PFC circuitry is dysregulated in depression and anxiety. These include alterations of structure, markers of glutamatergic and GABAergic neurotransmission, and connectivity with downstream structures [28]. Considering that previous studies have shown that respiratory rhythm could contribute to information processing in the frontal neuronal network [8,10], we speculate that the depression-anxiety-like behavior of the NRD mice might be caused by the dysregulation of the PFC neural network.

Nasal breathing has been linked to memory processes [12,29]. The hippocampus and amygdala are important brain areas associated with memory and are regulated by breathing signals [30]. In our study, NRD mice showed cognitive impairments in several learning and memory tests aimed to assess both hippocampal-dependent memory ( $Y$ maze, object recognition task, and the contextual fear conditioning) [17-19] and amygdaladependent memory (the tone-cued fear conditioning test) [30]. Results showed that the correct rate of autonomous alternation in Y maze decreased in the NRD mice, which did not cause by exploratory disposition. The ORT index of the NRD mice in the object recognition task decreased significantly, which is consistent with the features in the human memory experiment when only mouth breathing was retained [29]. Interestingly, in the training phase of the contextual fear conditioning test, when the mice were given 0.3-mA foot shock, the freezing time of the NRD group showed no significant difference compared to the control group, indicating that the NRD mice could successfully acquire contextual fear. Moreover, an increase in freezing time was observed in a 1-h and 24-h contextual memory retrieval test. These results suggest that the sensory deprivation of nasal respiratory can enhance hippocampal-dependent fear memory retrieval without affecting fear memory formation. Taken together, the hippocampal-dependent memory deficiency observed indicates that NRD mice acquired cognitive anomalies.

More notably, during the acquisition phase of the cued fear conditioning test, 0.5-mA foot shock caused parallel fear in the NRD group and control group. However, the NRD mice showed less freezing time during cued memory retrieval at $1 \mathrm{~h}$ and $24 \mathrm{~h}$ after the training. Cued fear is amygdala-dependent memory, suggesting that the sensory deprivation of nasal respiratory did not affect amygdala-dependent fear memory formation but is only responsible for the cued memory retrieval, consistent with a previous report [31]. Studies have described that amygdala, not $\mathrm{mPFC}$, plays a role in fear acquisition [32,33], but both play a role in fear expression [34,35]. Our research further supports the existence of two separate brain mechanisms controlling initiation and maintenance of freezing behavior independently.

As mentioned above, NRD can cause depression in mice, and depression can cause social withdrawal [36]. To investigate how NRD mice might behave, we performed a threecompartment test and found that the NRD mice showed both impaired social behavior and social novelty behavior. This could be due to a general change in cognition or a lack of interest in social novelty [37] or impairment of smell [38]. At the same time, we tested the mice using the von Frey filaments test and found that the pain sensitivity of olfactory impaired mice was decreased, indicating that nasal respiration plays a role in pain perception. Many brain areas are closely related to nasal breathing, such as the amygdala, somatosensory cortex, and prefrontal cortex [7-9], and are involved in the perception of pain [39-41]. Therefore, the decreased pain sensitivity caused by NRD may arise from abnormal neuron activity in these brain areas. 
In summary, this mouse model of NRD showed a variety of behavioral phenotypic changes, including depression-like behavior, anxiety-like behavior, cognitive impairments, impaired social behavior, social novelty behavior, and pain perception, indicating that nasal breathing may alter related behaviors by affecting the neural activity of the brain. Hence, relevant symptoms caused by abnormal nasal breathing sensory should be concerned when nasal breathing is limited or OB undergoes pathological changes, including malfunctions of the olfactory epithelium due to infections, such as COVID-19 [42], as well as neurodegenerative diseases [43], such as Alzheimer's disease, Parkinson's disease, etc.

\section{Conclusions}

Limitations

$\mathrm{ZnSO}_{4}$ nasal irrigation can impair the sense of smell of mice and will recover to a certain extent with time (Figure S1). For rodents that rely heavily on smell, this will lead to changes in some behavioral domains [44]. However, the odorant and the mechanical responses are mediated by a common cAMP cascade of olfactory sensory neurons [5]. Part of the reasons of behavioral changes caused by olfactory destruction, perhaps, is the destruction of nasal breathing perception. Therefore, the relationship between the two is also something that cannot be ignored in future research. Due to the regeneration characteristics of the olfactory epithelium, can the injured behavioral phenotype of the NRD mice be rescued following the recovery of the olfactory epithelium? Additionally, the difference of behavior may be partly related to the difference in endocrine status [45]. What is the difference in the behavioral changes of female mice between male mice after the sensory deprivation of nasal breathing? These have important guiding significance for related clinical symptoms and further researches are needed.

Supplementary Materials: The following are available online at https:/ / www.mdpi.com/article/10 .3390 /brainsci11121626/s1, Figure S1: Result shows that zinc sulfate irrigation will affect the sense of smell of mice, and will recover to a certain extent with time. ${ }^{* * *} p<0.001,{ }^{* * * *} p<0.0001$, Control vs NRD; \#\#\# $p<0.001$ NRD day 1 vs NRD day 7; Two-way ANOVA. $n$ (control) $=12, n(\mathrm{NRD})=12$.

Author Contributions: S.L. and W.L. contributed to the experimental design and writing the initial draft. Y.Z., Y.Y., and C.Z. contributed to performing the most behavioral experiments and the statistics, S.S., J.Z., and Z.Z. performed partial statistics. T.S., J.L., and J.Y. performed provided considerable manuscript review. All authors have read and agreed to the published version of the manuscript.

Funding: This work was supported by Zhejiang Basic Public Welfare Research Program (grant numbers LGD22H250001 and LGD21H250001) and Hangzhou Agriculture and Social development research project (grant numbers 20201203B149).

Institutional Review Board Statement: The study was conducted in accordance with the guidelines of the Declaration of Helsinki and was approved by the Animal Ethics Committee of Zhejiang University (protocol code: 20545 and approval date: 13 May 2021).

Informed Consent Statement: The study did not involve humans.

Data Availability Statement: The data provided in this study can be obtained from the corresponding author under reasonable request.

Acknowledgments: The authors are grateful to Huaqing Liu for their valuable assistance with experimental apparatus of von Frey filaments test and the analysis of the pain sensibility.

Conflicts of Interest: The authors declare that there is no potential conflict of interest.

\section{References}

1. Feldman, J.L.; Del Negro, C.A. Looking for inspiration: New perspectives on respiratory rhythm. Nat. Rev. Neurosci. 2006, 7, 232-242. [CrossRef] [PubMed]

2. Moberly, A.H.; Schreck, M.; Bhattarai, J.P.; Zweifel, L.S.; Luo, W.; Ma, M. Olfactory inputs modulate respiration-related rhythmic activity in the prefrontal cortex and freezing behavior. Nat. Commun. 2018, 9, 1528. [CrossRef]

3. Zelano, C.; Jiang, H.; Zhou, G.; Arora, N.; Schuele, S.; Rosenow, J.; Gottfried, J.A. Nasal Respiration Entrains Human Limbic Oscillations and Modulates Cognitive Function. J. Neurosci. 2016, 36, 12448-12467. [CrossRef] [PubMed] 
4. Goncalves, A.V.; Makuch, M.Y.; Setubal, M.S.; Barros, N.F.; Bahamondes, L. A Qualitative Study on the Practice of Yoga for Women with Pain-Associated Endometriosis. J. Altern. Complement. Med. 2016, 22, 977-982. [CrossRef]

5. Grosmaitre, X.; Santarelli, L.C.; Tan, J.; Luo, M.; Ma, M. Dual functions of mammalian olfactory sensory neurons as odor detectors and mechanical sensors. Nat. Neurosci. 2007, 10, 348-354. [CrossRef]

6. Yanovsky, Y.; Ciatipis, M.; Draguhn, A.; Tort, A.B.; Brankack, J. Slow oscillations in the mouse hippocampus entrained by nasal respiration. J. Neurosci. 2014, 34, 5949-5964. [CrossRef] [PubMed]

7. Zhong, W.; Ciatipis, M.; Wolfenstetter, T.; Jessberger, J.; Muller, C.; Ponsel, S.; Yanovsky, Y.; Brankack, J.; Tort, A.B.L.; Draguhn, A. Selective entrainment of gamma subbands by different slow network oscillations. Proc. Natl. Acad. Sci. USA. 2017, 114, 4519-4524. [CrossRef] [PubMed]

8. Biskamp, J.; Bartos, M.; Sauer, J.F. Organization of prefrontal network activity by respiration-related oscillations. Sci. Rep. 2017, 7, 45508. [CrossRef]

9. Ito, J.; Roy, S.; Liu, Y.; Cao, Y.; Fletcher, M.; Lu, L.; Boughter, J.D.; Grun, S.; Heck, D.H. Whisker barrel cortex delta oscillations and gamma power in the awake mouse are linked to respiration. Nat. Commun. 2014, 5, 3572. [CrossRef] [PubMed]

10. Tort, A.B.L.; Brankack, J.; Draguhn, A. Respiration-Entrained Brain Rhythms Are Global but Often Overlooked. Trends Neurosci. 2018, 41, 186-197. [CrossRef] [PubMed]

11. Zhuang, L.; Zhang, B.; Qin, Z.; Wang, P. Nasal Respiration is Necessary for the Generation of gamma Oscillation in the Olfactory Bulb. Neuroscience 2018, 398, 218-230. [CrossRef] [PubMed]

12. Liu, Y.; McAfee, S.S.; Heck, D.H. Hippocampal sharp-wave ripples in awake mice are entrained by respiration. Sci. Rep. 2017, 7 , 8950. [CrossRef] [PubMed]

13. Williams, S.K.; Gilbey, T.; Barnett, S.C. Immunohistochemical studies of the cellular changes in the peripheral olfactory system after zinc sulfate nasal irrigation. Neurochem. Res. 2004, 29, 891-901. [CrossRef]

14. Kraeuter, A.K.; Guest, P.C.; Sarnyai, Z. The Open Field Test for Measuring Locomotor Activity and Anxiety-Like Behavior. Methods Mol. Biol. 2019, 1916, 99-103. [CrossRef]

15. Morgan, J.A.; Singhal, G.; Corrigan, F.; Jaehne, E.J.; Jawahar, M.C.; Baune, B.T. The effects of aerobic exercise on depression-like, anxiety-like, and cognition-like behaviours over the healthy adult lifespan of C57BL/6 mice. Behav. Brain Res. 2018, 337, 193-203. [CrossRef] [PubMed]

16. Can, A.; Dao, D.T.; Arad, M.; Terrillion, C.E.; Piantadosi, S.C.; Gould, T.D. The mouse forced swim test. J. Vis. Exp. 2012, 59 , e3638. [CrossRef] [PubMed]

17. Johnson, C.T.; Olton, D.S.; Gage, F.H., 3rd; Jenko, P.G. Damage to hippocampus and hippocampal connections: Effects on DRL and spontaneous alternation. J. Comp. Physiol. Psychol. 1977, 91, 508-522. [CrossRef] [PubMed]

18. Cohen, S.J.; Stackman, R.W., Jr. Assessing rodent hippocampal involvement in the novel object recognition task. A review. Behav Brain Res. 2015, 285, 105-117. [CrossRef] [PubMed]

19. Saxe, M.D.; Battaglia, F.; Wang, J.W.; Malleret, G.; David, D.J.; Monckton, J.E.; Garcia, A.D.; Sofroniew, M.V.; Kandel, E.R.; Santarelli, L.; et al. Ablation of hippocampal neurogenesis impairs contextual fear conditioning and synaptic plasticity in the dentate gyrus. Proc. Natl. Acad. Sci. USA. 2006, 103, 17501-17506. [CrossRef]

20. He, X.; Li, J.; Zhou, G.; Yang, J.; McKenzie, S.; Li, Y.; Li, W.; Yu, J.; Wang, Y.; Qu, J.; et al. Gating of hippocampal rhythms and memory by synaptic plasticity in inhibitory interneurons. Neuron 2021, 109, 1013-1028.e9. [CrossRef] [PubMed]

21. Faizi, M.; Bader, P.L.; Saw, N.; Nguyen, T.V.; Beraki, S.; Wyss-Coray, T.; Longo, F.M.; Shamloo, M. Thy1-hAPP(Lond/Swe+) mouse model of Alzheimer's disease displays broad behavioral deficits in sensorimotor, cognitive and social function. Brain Behav. 2012, 2, 142-154. [CrossRef]

22. Chaplan, S.R.; Bach, F.W.; Pogrel, J.W.; Chung, J.M.; Yaksh, T.L. Quantitative assessment of tactile allodynia in the rat paw. J. Neurosci. Methods 1994, 53, 55-63. [CrossRef]

23. Li, S.; Li, W.; Wu, X.; Li, J.; Yang, J.; Tu, C.; Ye, X.; Ling, S. Olfactory deficit is associated with mitral cell dysfunction in the olfactory bulb of P301S tau transgenic mice. Brain Res. Bull. 2019, 148, 34-45. [CrossRef] [PubMed]

24. Baroncelli, L.; Alessandri, M.G.; Tola, J.; Putignano, E.; Migliore, M.; Amendola, E.; Gross, C.; Leuzzi, V.; Cioni, G.; Pizzorusso, T. A novel mouse model of creatine transporter deficiency. F1000Res. 2014, 3, 228. [CrossRef]

25. Kalawski, J.P. The Alba Method and the Science of Emotions. Integr. Psychol. Behav. Sci. 2020, 54, 903-919. [CrossRef]

26. Homma, I.; Masaoka, Y. Breathing rhythms and emotions. Exp. Physiol. 2008, 93, 1011-1021. [CrossRef] [PubMed]

27. Zaccaro, A.; Piarulli, A.; Laurino, M.; Garbella, E.; Menicucci, D.; Neri, B.; Gemignani, A. How Breath-Control Can Change Your Life: A Systematic Review on Psycho-Physiological Correlates of Slow Breathing. Front. Hum. Neurosci. 2018, 12, 353. [CrossRef]

28. Hare, B.D.; Duman, R.S. Prefrontal cortex circuits in depression and anxiety: Contribution of discrete neuronal populations and target regions. Mol. Psychiatry 2020, 25, 2742-2758. [CrossRef] [PubMed]

29. Arshamian, A.; Iravani, B.; Majid, A.; Lundstrom, J.N. Respiration Modulates Olfactory Memory Consolidation in Humans. J. Neurosci. 2018, 38, 10286-10294. [CrossRef] [PubMed]

30. Phillips, R.G.; LeDoux, J.E. Differential contribution of amygdala and hippocampus to cued and contextual fear conditioning. Behav. Neurosci. 1992, 106, 274-285. [CrossRef] [PubMed]

31. Bagur, S.; Lefort, J.M.; Lacroix, M.M.; de Lavilleon, G.; Herry, C.; Chouvaeff, M.; Billand, C.; Geoffroy, H.; Benchenane, K. Breathing-driven prefrontal oscillations regulate maintenance of conditioned-fear evoked freezing independently of initiation. Nat. Commun. 2021, 12, 2605. [CrossRef] 
32. Marek, R.; Strobel, C.; Bredy, T.W.; Sah, P. The amygdala and medial prefrontal cortex: Partners in the fear circuit. J. Physiol. 2013, 591, 2381-2391. [CrossRef] [PubMed]

33. Goosens, K.A.; Maren, S. NMDA receptors are essential for the acquisition, but not expression, of conditional fear and associative spike firing in the lateral amygdala. Eur. J. Neurosci. 2004, 20, 537-548. [CrossRef] [PubMed]

34. Corcoran, K.A.; Quirk, G.J. Activity in prelimbic cortex is necessary for the expression of learned, but not innate, fears. J. Neurosci. 2007, 27, 840-844. [CrossRef] [PubMed]

35. Anglada-Figueroa, D.; Quirk, G.J. Lesions of the basal amygdala block expression of conditioned fear but not extinction. J. Neurosci. 2005, 25, 9680-9685. [CrossRef]

36. Knight, M.J.; Baune, B.T. Cognitive dysfunction in major depressive disorder. Curr. Opin. Psychiatry 2018, 31, 26-31. [CrossRef]

37. Kupferberg, A.; Bicks, L.; Hasler, G. Social functioning in major depressive disorder. Neurosci. Biobehav. Rev. 2016, 69, 313-332. [CrossRef] [PubMed]

38. Wacker, D.W.; Ludwig, M. Vasopressin, oxytocin, and social odor recognition. Horm. Behav. 2012, 61, 259-265. [CrossRef]

39. Ossipov, M.H.; Dussor, G.O.; Porreca, F. Central modulation of pain. J. Clin. Invest. 2010, 120, 3779-3787. [CrossRef] [PubMed]

40. Ong, W.Y.; Stohler, C.S.; Herr, D.R. Role of the Prefrontal Cortex in Pain Processing. Mol. Neurobiol. 2019, 56, 1137-1166. [CrossRef] [PubMed]

41. Fields, H.L. Pain and the primary somatosensory cortex. Pain 2012, 153, 742-743. [CrossRef] [PubMed]

42. Luers, J.C.; Rokohl, A.C.; Loreck, N.; Wawer Matos, P.A.; Augustin, M.; Dewald, F.; Klein, F.; Lehmann, C.; Heindl, L.M. Olfactory and Gustatory Dysfunction in Coronavirus Disease 2019 (COVID-19). Clin. Infect. Dis. 2020, 71, 2262-2264. [CrossRef] [PubMed]

43. Dan, X.; Wechter, N.; Gray, S.; Mohanty, J.G.; Croteau, D.L.; Bohr, V.A. Olfactory dysfunction in aging and neurodegenerative diseases. Ageing Res. Rev. 2021, 70, 101416. [CrossRef] [PubMed]

44. Ahn, S.; Choi, M.; Kim, H.; Yang, E.J.; Mahmood, U.; Kang, S.I.; Shin, H.W.; Kim, D.W.; Kim, H.S. Transient Anosmia Induces Depressive-like and Anxiolytic-like Behavior and Reduces Amygdalar Corticotropin-Releasing Hormone in a ZnSO4-Induced Mouse Model. Chem. Senses 2018, 43, 213-221. [CrossRef] [PubMed]

45. Kass, M.D.; Czarnecki, L.A.; Moberly, A.H.; McGann, J.P. Differences in peripheral sensory input to the olfactory bulb between male and female mice. Sci. Rep. 2017, 7, 45851. [CrossRef] [PubMed] 